\title{
Quality of life among caregivers of people with end-stage kidney disease managed with dialysis or comprehensive conservative care
}

Karan K. Shah ${ }^{1 *}$ (D) Fliss E. M. Murtagh ${ }^{2}$, Kevin McGeechan ${ }^{3}$, Susan M. Crail ${ }^{4}$, Aine Burns ${ }^{5}$ and Rachael L. Morton ${ }^{1}$

\begin{abstract}
Background: To measure health-related and care-related quality of life among informal caregivers of older people with end-stage kidney disease (ESKD), and to determine the association between caregiver quality of life and care recipient's treatment type.

Methods: A prospective cross-sectional study was conducted. Three renal units in the UK and Australia were included. Informal caregivers of people aged $\geq 75$ years with ESKD managed with dialysis or comprehensive conservative non-dialytic care (estimated glomerular filtration (eGFR) $\leq 10 \mathrm{~mL} / \mathrm{min} / 1.73 \mathrm{~m}^{2}$ ) participated. Healthrelated quality of life (HRQoL) was assessed using Short-Form six dimensions (SF-6D, 0-1 scale) and care-related quality of life was assessed using the Carer Experience Scale (CES, 0-100 scale). Linear regression assessed associations between care-recipient treatment type, caregiver characteristics and the SF-6D utility index and CES scores.

Results: Of 63 caregivers, 49 (78\%) were from Australia, 26 (41\%) cared for an older person managed with dialysis, and 37 (59\%) cared for an older person managed with comprehensive conservative care. Overall, $73 \%$ were females, and the median age of the entire cohort was 76 years [IQR 68-81]. When adjusted for caregiver sociodemographic characteristics, caregivers reported significantly worse carer experience (CES score 15.73, 95\% Cl 5.78 to 25.68) for those managing an older person on dialysis compared with conservative care. However, no significant difference observed for carer HRQoL (SF-6D utility index $-0.08,95 \% \mathrm{Cl}-0.18$ to 0.01 ) for those managing an older person on dialysis compared with conservative care.

Conclusions: Our data suggest informal caregivers of older people on dialysis have significantly worse care-related quality of life (and therefore greater need for support) than those managed with comprehensive conservative care. It is important to consider the impact on caregivers' quality of life when considering treatment choices for their care recipients.
\end{abstract}

Keywords: Informal caregivers, Chronic renal insufficiency, Quality of life, Renal Dialysis, Conservative care

\footnotetext{
* Correspondence: karan.shah@ctc.usyd.edu.au

${ }^{1}$ National Health and Medical Research Council (NHMRC) Clinical Trials

Centre, The University of Sydney, 92-94 Parramatta Road, Camperdown, NSW 2050, Australia

Full list of author information is available at the end of the article
}

(c) The Author(s). 2020 Open Access This article is licensed under a Creative Commons Attribution 4.0 International License, which permits use, sharing, adaptation, distribution and reproduction in any medium or format, as long as you give appropriate credit to the original author(s) and the source, provide a link to the Creative Commons licence, and indicate if changes were made. The images or other third party material in this article are included in the article's Creative Commons licence, unless indicated otherwise in a credit line to the material. If material is not included in the article's Creative Commons licence and your intended use is not permitted by statutory regulation or exceeds the permitted use, you will need to obtain permission directly from the copyright holder. To view a copy of this licence, visit http://creativecommons.org/licenses/by/4.0/. The Creative Commons Public Domain Dedication waiver (http://creativecommons.org/publicdomain/zero/1.0/) applies to the data made available in this article, unless otherwise stated in a credit line to the data. 


\section{Background}

Older people with end-stage kidney disease (ESKD) managed with dialysis have ageing-related health and social care needs, and a high likelihood of developing frailty syndrome within a few months of starting dialysis [1-4]. Informal care of older people or those with chronic disease is largely provided by their family members and close friends [5]. Informal care tasks include assistance with activities of daily living, support with mobility, transportation, social support and personal care (e.g. washing and dressing). Although generally unpaid, some caregivers may receive a nominal payment or state benefits [6].

Observational data suggest dialysis may not extend life in the very old, or those with multiple comorbidities and poor physical function [1,7-9] and it is not surprising a high proportion of older people choose comprehensive conservative care (i.e. no dialysis but active supportive care) in health systems where this option is actively discussed, (Canada, the UK and Australia) [1, 10, 11]. With the rapidly growing number of elderly people with ESKD and those with comorbid conditions receiving kidney replacement therapy, the burden on informal caregivers (i.e. close friends or family) to provide care and support has increased [12].

Caregiving demands in managing dialysis has proved to be taxing on the physical, social and emotional health of informal caregivers [12, 13]. Previous research shows that caregivers may experience depression, anxiety, fatigue, social isolation, relationship strains, financial difficulties and stress due to the added responsibility of managing their care recipient's treatment, dietary requirements, clinic appointments and psychosocial issues [13-21]. However, robust comparative evidence on the health-related and care-related quality of life of informal caregivers of older people managed with dialysis or comprehensive conservative care is limited. This is important because family members are actively encouraged to participate in ESKD modality decision-making - and they need to be informed. Furthermore, many patients also consider the potential impact on their close persons in making decisions about treatment $[22,23]$.

Previous economic evaluations of healthcare interventions for caregivers have limited the assessment of health benefit to solely health-related quality of life (HRQoL) [5, 24-28]. These benefits were typically measured in utility weights, also called health state preferences that are combined with survival time to obtain qualityadjusted life-years (QALYs). However, it should be noted that QALYs were not developed to capture caregivers quality of life and previous research suggests that they may be insensitive to psychological and broader effects of caregiving [5, 29-31]. Other HRQoL measures included specific "sum score" measures of carer quality of life such as the Carer Strain Index (not preferencebased) and Sense of Competence Questionnaire (validated for informal caregivers of patients with diagnosed dementia and stroke) [5, 32, 33].

The Carer Experience Scale (CES) was constructed to record the caring experience, calculate caregiver quality of life, and could be used in the assessment of interventions targeted towards caregivers [5, 34]. The CES produces a single score reflecting the overall effect of caregiving and is preference weighted (i.e. constitutes the value or desirability of caregivers of older people in the UK) that quantifies the relative importance of the caregiving domains, where some caring tasks might be perceived more burdensome than others [5].

We aimed to assess and compare the health-related quality of life (the gold standard required for economic evaluations) and care-related quality of life among informal caregivers of older people with ESKD, managed with dialysis or comprehensive conservative care; and explore associations between the caregiver's quality of life and care recipient's treatment type.

\section{Methods \\ Study design}

We conducted a multicentre prospective cross-sectional study in two countries of informal caregivers of older people with ESKD treated with dialysis or comprehensive conservative care, between 2014 and 2017. The study was performed in accordance with the Australian National Statement on Ethical Conduct in Human Research (2007), and National Research Ethics guidance in the UK. Each renal unit participating in the study obtained the approval of the Institutional Health Research Ethics Committee to conduct the study. The study was reported using Strengthening the Reporting of Observational Studies in Epidemiology (STROBE) guidelines for observational studies (Additional file item 1) [35].

\section{Setting and participants}

The study was undertaken at three tertiary renal units in the UK and Australia [36]. Patients aged $\geq 75$ years with ESKD, managed with dialysis (facility haemodialysis, home haemodialysis, or peritoneal dialysis); or managed with comprehensive conservative, non-dialytic care and with an estimated glomerular filtration (eGFR) $\leq 10 \mathrm{ml} /$ $\min / 1.73 \mathrm{~m}^{2}$, were asked to nominate one or more of their informal caregivers (i.e. partners, siblings, relatives, or close friends) to participate. Caregivers present at appointments were invited to participate. In addition, patients who participated took an information sheet home for their caregivers and if interested were invited to participate. One renal unit mailed out surveys if the patient thought their caregiver may be interested. Interested caregivers were asked to sign the consent form and 
provided with the survey booklet consisting of SF-12 (Additional file item 2) and CES questionnaire (Additional file item 3) along with questions assessing their sociodemographic characteristics (Additional file item 4).

\section{Variables}

The main outcome variables were the caregiver SF-6D utility (a generic preference-based single measure of HRQoL) on a 0 to 1 scale (death to full health, where a higher utility scores indicate higher HRQoL), and CES scores (measure of care-related quality of life) on a 0 to 100 scale ('worst caring experience' to 'best experience', where higher scores indicate higher care-related quality of life).

The SF-12 responses were transformed into HRQoL weights, known as utilities, using a published SF-6D algorithm [37]. The SF-6D encompasses six multilevel dimensions: "physical functioning, role limitations, social functioning, pain, mental health, and vitality". The SF-6D utilities were calculated using UK population values [37-39].

The CES preference-based questionnaire measures care-related quality of life and consists of six dimensions of caregiving: " [1] activities outside caring [2]; support from family and friends (social support) [3]; assistance from organizations and the government (institutional support) [4]; fulfilment from caring [5]; control over caring and [6] getting-on with the care recipient" [34, 40]. It has three-level response options, representing three levels of caregiver experience. The CES produces a single score reflecting the overall effect of caregiving and is preference weighted (using UK population tariffs) [5].

\section{Data sources/measurement}

Data were collected using a pen and paper-based survey at a single time point (cross-sectional).

\section{Study size}

The study did not require a specific power calculation as the sample size was determined by the requirements of the original ICECAP-O study [36] assessing patient quality of life and wellbeing. Multiple caregivers attached to a single older person with ESKD were permitted to participate, given the known difficulties in identifying and recruiting informal caregivers to research studies.

\section{Quantitative variables}

The SF-6D utilities, CES scores, and caregivers' age were treated as continuous, while caregivers' sex, country (UK, Australia), care recipient treatment type (dialysis, conservative care), education level (some high school or lower, completed high school or higher), private health insurance (yes, no), care recipient length of kidney disease (less than 1 year, 1-2 years, more than 2 years), length of caring ( $0-2$ years, more than 2 years), type of relationship to the care recipient (spouse/partner, child, sibling, other) were analysed as categorical variables. Age was additionally dichotomised (less than or equal to, versus greater than the median age [76 years]).

\section{Statistical methods}

Descriptive statistics were used to assess proportions and mean values of SF-6D utilities, and the CES score. Chi-square test was used to determine the differences in proportion of caregiver characteristics. Hypothesis testing with a two-tailed Student's t-test was used to determine associations in mean values of SF-6D utilities, and CES score by care recipient treatment type and caregiver socio-demographic characteristics. One-way Analysis of Variance (ANOVA) was used to determine differences in the means for 'type of relationship with the care recipient' variable with three independent categories. Generalised linear regression with multivariable models (GLM) was undertaken to determine the association between care recipient treatment type on SF-6D utilities, and CES scores, adjusted for caregiver characteristics. Age, sex, country, education, private health insurance, care recipient treatment type, care recipient's duration of kidney disease, length of caring, and type of relationship with care recipient were included as covariates on the basis of a priori knowledge of their associations with the HRQoL and care-related quality of life.

Complete case analysis was performed for all outcomes. All analyses were undertaken with SAS Version 9.4 (SAS Institute, Cary, NC). A $p$-value of $<0.05$ was considered statistically significant.

\section{Results}

A total of 63 caregivers were enrolled (Additional file figure 1), 49 (78\%) were from Australia, 26 (41\%) cared for an older person managed with dialysis, and 37 (59\%) cared for an older person managed with comprehensive conservative care. Overall, $73 \%$ were females, and the median age of the entire cohort was 76 years [IQR 68-81]. Overall, the conservative care group had higher rate of children performing the caring $(p=0.01)$; Australian participants $(p=0.05)$; and care recipients with kidney disease for more than 2 years $(p=0.006)$ compared with the dialysis group. Caregiver characteristics are shown in Table 1.

\section{Health-related quality of life (SF-6D utility index)}

Of 63 informal caregivers, the mean utility for 58 with complete data was 0.74 (SD 0.13). The mean utility of caregivers of patients managed with dialysis was 0.70 (SD 0.13), and 0.77 (SD 0.12) for those caring for conservative care patients (Additional file Table 1). The "vitality" domain reported the highest average score and 
Table 1 Caregiver characteristics according to care recipient treatment group

\begin{tabular}{|c|c|c|c|c|}
\hline Caring Context & $\begin{array}{l}\text { Dialysis } \\
\boldsymbol{n}=26 \\
\mathrm{n}(\%)\end{array}$ & $\begin{array}{l}\text { Conservative Care } \\
\boldsymbol{n}=37 \\
\mathrm{n}(\%)\end{array}$ & $\begin{array}{l}\text { Total } \\
\boldsymbol{n}=63 \\
\mathrm{n}(\%)\end{array}$ & $\boldsymbol{P}$ value \\
\hline Caregivers of care recipient on dialysis & & & & - \\
\hline Facility Hemodialysis & $13(50 \%)$ & - & $13(21 \%)$ & \\
\hline Home Hemodialysis & $1(4 \%)$ & - & $1(2 \%)$ & \\
\hline Peritoneal Dialysis & $12(46 \%)$ & - & $12(19 \%)$ & \\
\hline Median age $(y)$ & $76[70-79]$ & 76 [68-82] & $76[68-81]$ & \\
\hline Age group & & & & 0.62 \\
\hline$\leq 76$ years & $15(58 \%)$ & $19(51 \%)$ & $34(54 \%)$ & \\
\hline$>76$ years & $11(42 \%)$ & $18(49 \%)$ & $29(46 \%)$ & \\
\hline Gender & & & & 0.56 \\
\hline Males & $6(23 \%)$ & $11(30 \%)$ & $17(27 \%)$ & \\
\hline Females & $20(77 \%)$ & $26(70 \%)$ & $46(73 \%)$ & \\
\hline Health System & & & & $0.05^{*}$ \\
\hline United Kingdom & $9(35 \%)$ & $5(14 \%)$ & $14(22 \%)$ & \\
\hline Australia & $17(65 \%)$ & $32(86 \%)$ & $49(78 \%)$ & \\
\hline Education & & & & 0.68 \\
\hline Primary school & $5(19 \%)$ & $10(27 \%)$ & $15(24 \%)$ & \\
\hline Some high school & $7(27 \%)$ & $11(30 \%)$ & $18(28 \%)$ & \\
\hline Completed high school & $6(23 \%)$ & $7(19 \%)$ & $13(21 \%)$ & \\
\hline Completed diploma & $3(12 \%)$ & $6(16 \%)$ & $9(14 \%)$ & \\
\hline Completed university degree & $5(19 \%)$ & $3(8 \%)$ & $8(13 \%)$ & \\
\hline Private health insurance & & & & 0.90 \\
\hline Yes & $17(65 \%)$ & $25(67 \%)$ & $42(67 \%)$ & \\
\hline No & $8(31 \%)$ & $11(30 \%)$ & $19(30 \%)$ & \\
\hline Unknown & $1(4 \%)$ & $1(3 \%)$ & $2(3 \%)$ & \\
\hline Care recipient length of kidney disease & & & & $0.006^{*}$ \\
\hline$<1$ year & $2(8 \%)$ & - & $2(3 \%)$ & \\
\hline $1-2$ years & $5(19 \%)$ & - & $5(8 \%)$ & \\
\hline$>2$ years & $19(73 \%)$ & $34(100 \%)$ & $53(88 \%)$ & \\
\hline Length of care & & & & 0.23 \\
\hline $0-2$ years & $7(28 \%)$ & $5(15 \%)$ & $12(21 \%)$ & \\
\hline$>2$ years & $18(72 \%)$ & $28(85 \%)$ & $46(79 \%)$ & \\
\hline Type of relationship & & & & $0.01^{*}$ \\
\hline Spouse/Partner & $19(73 \%)$ & $20(63 \%)$ & $39(67 \%)$ & \\
\hline Child & - & $9(28 \%)$ & $9(16 \%)$ & \\
\hline Sibling & $1(4 \%)$ & - & $1(1 \%)$ & \\
\hline Other & $6(23 \%)$ & $3(9 \%)$ & $9(16 \%)$ & \\
\hline
\end{tabular}

${ }^{*} p<0.05$, statistical significance

was responsible for the highest decrement in utilities for caregivers of the patients managed with dialysis or conservative care (Additional file Table 2).

When adjusted for other variables, there was no significant difference by care recipient treatment type (Table 2).
Care-related quality of life (CES scores)

Of 63 caregivers, the mean CES score for 61 with complete data was 74.41 (SD 17.67). The mean CES score of caregivers for patients managed with dialysis was 64.39 (16.75), and 80.91 (SD 15.20) for those caring for comprehensive conservative care patients (Additional 
Table 2 Adjusted differences in SF-6D utility according to caregiver sociodemographic characteristics and care recipient treatment group

\begin{tabular}{|c|c|c|c|c|}
\hline & Differences & 95\% Lower Cl & 95\% Upper Cl & $p$ value \\
\hline Age $(Y)$ & -0.002 & -0.007 & 0.002 & 0.34 \\
\hline Gender & -0.04 & -0.13 & 0.05 & 0.36 \\
\hline Care recipient treatment & -0.08 & -0.18 & 0.01 & 0.09 \\
\hline Health System & -0.05 & -0.15 & 0.06 & 0.36 \\
\hline Education & 0.04 & -0.06 & 0.13 & 0.44 \\
\hline Private health insurance & 0.006 & -0.09 & 0.10 & 0.89 \\
\hline Care recipient length of kidney disease & -0.08 & -0.26 & 0.10 & 0.37 \\
\hline Length of care & 0.07 & -0.05 & 0.19 & 0.23 \\
\hline Relationship type & -0.0006 & -0.12 & 0.12 & 0.99 \\
\hline
\end{tabular}

The reference category for the difference are as follow: Age (every unit increase), Gender (male - female), Care recipient treatment (conservative care - dialysis), Country (UK-Australia), Education (completed high school or tertiary education - attended some high school or lower levels), Private health insurance (Yes - No/ Unknown), Care recipient length of kidney disease ( $\leq 2$ years - $>2$ years), Length of care ( $0-2$ years $->2$ years), Relationship type (Spouse/Partner - Child, sibling and other). SF-6D - Short Form six dimensions. $\mathrm{Cl}$ - Confidence interval

file Table 1). The CES domain, "Getting on with the person you care for" reported the highest average score and was responsible for the greatest increment in overall CES score (Additional file Table 2).

In the univariate analyses, the mean CES score was 16.53 points lower for caregivers of dialysis patients than for comprehensive conservative care patients ( $p=$ 0.0002); and was 18.76 points lower for caregivers residing in the UK compared with Australia $(p=0.0003)$ (Additional file Table 1). Significant lower mean CES scores were observed for the spouse/partner compared with children of care recipients (Additional file Table 3).

When adjusted for other variables, the mean CES score was 15.73 points lower for caregivers of patients on dialysis compared with caregivers of patients on comprehensive conservative care $(p=0.003)$ (Table 3$)$; and was 16.19 points lower for caregivers in the UK compared with Australia ( $p=0.004)$ (Table 3).

\section{Discussion}

The findings of this study give an insight into healthrelated and care-related quality of life of informal caregivers of older people with ESKD managed with dialysis or conservative care. Our prospective cross-sectional study suggests a significantly lower care-related quality of life for informal caregivers of older people on dialysis compared with those on conservative care, and those residing in the UK compared with those residing in Australia. However, no significant difference in HRQoL of the caregivers by care recipient treatment type or for any caregiver sociodemographic characteristics was observed. Providing care has a complex range of effects on caregiver's quality of life and HRQoL instruments were specifically developed for measuring the impact of health and medical interventions on a patient's quality of life rather than their caregiver's [29, 41]. The lack of statistical significance in the HRQoL estimates could be

Table 3 Adjusted differences in CES score according to caregiver sociodemographic characteristics and care recipient treatment group

\begin{tabular}{lllll}
\hline & Differences & $95 \%$ Lower Cl & $95 \%$ Upper Cl & 0.49 \\
\hline Age $(Y)$ & 0.01 & -0.47 & 7.61 & 0.96 \\
Gender & -1.81 & -11.23 & -5.78 & 0.70 \\
Care recipient treatment & -15.73 & -25.68 & 26.75 & $0.003^{*}$ \\
Health System & 16.19 & 5.63 & 8.36 & 0.74 \\
Education & -1.67 & -11.70 & 18.69 & 0.19 \\
Private health insurance & 7.45 & -3.79 & 4.70 & 0.13 \\
Care recipient length of kidney disease & -15.52 & -35.73 & 9.16 & 0.55 \\
Length of care & -3.98 & -17.11 & 16.83 & 0.49 \\
Relationship type & 4.31 & -8.22 &
\end{tabular}

The reference category for the difference are as follow: Age (every unit increase), Gender (male - female), Care recipient treatment (conservative care - dialysis), Country (UK-Australia), Education (completed high school or tertiary education - attended some high school or lower levels), Private health insurance (Yes - No/ Unknown), Care recipient length of kidney disease ( $\leq 2$ years $->2$ years), Length of care ( $0-2$ years $->2$ years), Relationship type (Spouse/Partner - Child, sibling and other). CES - Carer Experience Scale. ${ }^{*} p<0.05$, statistical significance. $\mathrm{Cl}$ - Confidence interval 
attributed to the instrument's insensitivity in measuring the effects of interventions on caregiver's quality of life.

The caregivers of dialysis patients reported a mean CES score that was significantly lower than those caring for conservative care patients. A higher CES score indicates a higher care-related quality of life. The population norms for the CES scores are not available yet. However, a study into the construct validity of the CES in a heterogeneous group of carers in the UK presented mean CES scores and by category including duration of caring ( $<20 \mathrm{~h}$ or $\geq 20 \mathrm{~h}$ per week), recipient's health (bad, good to fair), and intensity of caring (not intense, relatively intense, intense) [42]. When comparing our study derived CES scores, it can be seen that the mean scores of caregivers of dialysis patients were consistent with providing an 'intense' level of care; to care recipient's in 'bad' health; and for a caring duration $\geq 20 \mathrm{~h}$ per week [42].

The caregivers of dialysis patients reported a slightly lower utility $(-0.08)$ compared with the conservative care group reflecting a potentially clinically meaningful important difference related to treatment; however, this difference was not statistically significant. Meaningful differences or the minimal important difference (MID) in utility-based HRQoL reported in 11 studies using the SF-6D utilities, ranged from 0.011 to 0.097 , with a mean MID of 0.041 [43]. It is therefore likely our study did detect a meaningful difference. In addition, the caregivers of dialysis patients reported a significant difference of - 15.73 in the CES score compared with conservative care group; however, the MIDs for CES has not yet been published. The lower CES score for caregivers of dialysis patients compared with those for conservative care patients observed in our study likely indicates the lower care-related quality of life.

The vitality domain representing energy/fatigue was observed to be the key driver affecting the HRQoL of caregivers of both the patient groups. It was reported to be much worse in the caregivers of dialysis patients compared with caregivers of conservative care patients, suggesting caregivers experiencing severe tiredness/fatigue as a result of providing care. We also observed that caregivers of dialysis patients had worse mental health scores compared with the caregivers of conservative care patients indicating poorer mental health. We could not find any studies comparing these two treatment groups specifically, but found previous studies reporting greater impairment to mental health and vitality domains of HRQoL of caregivers of dialysis patients [12, 44, 45]. In the care-related quality of life, we observed that the domain of 'assistance from organisations and government' received lower scores in both treatment groups compared with other domains. These suggest that caregivers may benefit from extra support, especially where the patient has a low HRQoL. Since some people may be reluctant to identify themselves as caregivers, limiting their ability to access support, health and social care professionals can play a role by encouraging caregivers to seek support [46] and signposting relevant help. Overall, we observed that the caregivers of conservative care patients reported higher scores for other domains such as 'activities outside caring', 'support from friends and family', and 'control over caring'.

This study should be interpreted in the context of several limitations. First, no data on the caregiver's comorbidities were collected. Considering the mean age of caregivers in this study, it is likely they might have some health problems. However, due to unavailability of the data, it was difficult to understand whether the strain of providing informal care lead to reductions in HRQoL, or whether people with health problems who become informal caregivers, perceived their tasks as being more straining [47]. Second, some differences in carer quality of life may be a result of the recipient's dialysis modality. Our study did not have sufficient numbers of patients on peritoneal dialysis and haemodialysis to facilitate a meaningful comparison. Third, the cross-sectional design of the study does not allow inferences about the causality of health losses due to caregiving. Further research of the HRQoL of informal caregivers should be undertaken in longitudinal and controlled trials. Fourth, we only recruited 63 caregivers and a specific power calculation was not performed as the sample size was determined by the requirements of the original ICECAP-O study [36]. Although there could be a statistically significant difference in the mean scores, the study may not have been able to capture it due to smaller sample size. However, recruiting informal caregivers to research is a known challenge [48, 49]. Fifth, the study identified the principal caregiver of a patient, however, caregiving may also be shared around many relatives and friends. In this case, considering outcomes for a sole caregiver for each patient may understate the degree of spillover effects a healthcare intervention may have [29]. Finally, we did not have information on patient/caregiver's ethnicity, a factor known to impact caregivers' satisfaction with caregiving for older family members.

\section{Conclusion}

The findings of this study suggest a lower care-related quality of life and greater need for support among informal caregivers of older patients with ESKD managed with dialysis compared with comprehensive conservative care. It is important to consider the impact on caregivers' quality of life when considering treatment choices for their care recipients. Furthermore, measuring carerelated quality of life using the CES alongside generic HRQoL measures, has the potential to provide a more detailed profile of the quality of life impacts on caregivers of older people with ESKD. 


\section{Supplementary information}

Supplementary information accompanies this paper at https://doi.org/10. 1186/s12882-020-01830-9.

Additional file 1: Table S1. SF-6D utility and CES score according to caregiver characteristics and care recipient treatment group. SF-6D utility and CES scores for caregiver sociodemographic characteristic and care recipient treatment type. Hypothesis testing using t-test employed. Table S2. Mean scores and weights of SF-6D and Carer Experience Scale (CES) according to care recipient treatment group. Mean scores and weights for different domains of SF-6D and CES scale provided according to care recipient treatment type. Table S3. Differences in SF-6D utility and CES score based on the type of relationship with the care recipient. ANOVA analysis for the type of relationship variable (three categories - Spouse/ Partner, Child, Others) for differences in SF-6D utility and CES score.

Additional file 2: Figure S1. Caregivers/patients flowchart. Flowchart on the number of caregivers included

Additional file 3. Item 1. STROBE Statement: checklist of items that should be included in reports of observational studies. STROBE checklist for cross-sectional studies for adequate and complete reporting of the study.Item 2. SF-12: Questionnaire (converted to SF-6D utilities). Administered to the caregivers. Item 3. Caregiver Experience Scale. Administered to the caregivers. Item 4. Background questions: (Caregivers). Administered to the caregivers.

\section{Abbreviations}

ESKD: End stage kidney disease; HRQoL: Health related quality of life; QALY: Quality adjusted life year; CES: Carer Experience Scale; SF-6D: Short Form Six Dimensions; SF-12: Short Form Survey 12 item; MID: Minimal important difference

\section{Acknowledgements}

The authors gratefully acknowledge the informal caregivers who participated in this study; and the research nurses from the UK and Australian renal units.

\section{Authors' contributions}

Authors FM, KM, SC, AB, and RM designed the study. RM, SC and AB led the data collection. KS conducted the analysis and drafted the first version of the manuscript. RM and KM supported the data analysis and interpretation of the results, and all authors helped in drafting and approved the final version of the manuscript.

\section{Funding}

This work was supported by the NHMRC Early Career Researcher Fellowship and Sidney Sax - Public Health Overseas Fellowship (1054216) grant awarded to Rachael Morton for the conduct of the ICECAP-O study. Karan Shah is employed at the NHMRC Clinical Trials Centre, University of Sydney, and is fully funded by the institution. The remaining authors declare that they have no other relevant financial interests. The funders had no role in the design, analysis and interpretation of data.

\section{Availability of data and materials}

The datasets generated and/or analysed during the current study are not publicly available but are available from the corresponding author on reasonable request.

\section{Ethics approval and consent to participate}

Each renal unit participating in the study obtained the approval of the Institutional Health Research Ethics Committee to conduct the study. All interested study participants were asked to provide written informed consent and sign the consent form.

\section{Consent for publication}

Not applicable.

\section{Competing interests}

None of the authors declares a conflict of interest. The results presented in this paper have not been published previously elsewhere, in either whole or part.

\section{Author details}

'National Health and Medical Research Council (NHMRC) Clinical Trials Centre, The University of Sydney, 92-94 Parramatta Road, Camperdown, NSW 2050, Australia. ${ }^{2}$ Wolfson Palliative Care Research Centre, Hull York Medical School, University of Hull, Kingston upon Hull, UK. ${ }^{3}$ School of Public Health, The University of Sydney, Sydney, NSW, Australia. ${ }^{4}$ Royal Adelaide Hospital, Adelaide, SA, Australia. ${ }^{5}$ Royal Free Hospital, London NHS Foundation Trust, London, UK.

Received: 8 October 2019 Accepted: 27 April 2020

Published online: 04 May 2020

\section{References}

1. Iyasere O, Brown EA, Johansson L, Davenport A, Farrington K, Maxwell $A P$, et al. Quality of life with conservative care compared with assisted peritoneal dialysis and haemodialysis. Clin Kidney J. 2019; 12(2):262-8.

2. Jassal SV, Chiu E, Hladunewich M. Loss of independence in patients starting dialysis at 80 years of age or older. N Engl J Med. 2009;361(16):1612-3.

3. Johansen $\mathrm{KL}$, Chertow GM, Jin C, Kutner NG. Significance of frailty among dialysis patients. J Am Soc Nephrol. 2007;18(11):2960-7.

4. Roshanravan B, Khatri M, Robinson-Cohen C, Levin G, Patel KV, de Boer $\mid H_{\text {, }}$ et al. A prospective study of frailty in nephrology-referred patients with CKD. Am J Kidney Dis. 2012;60(6):912-21.

5. Al-Janabi H, Flynn TN, Coast J. Estimation of a preference-based carer experience scale. Med Decis Mak. 2011:31(3):458-68.

6. Weatherly H, Faria R, Van Den Berg B. Valuing informal care for economic evaluation: Encyclopedia of Health Economics. United States: Elsevier; 2014. https://www.sciencedirect.com/referencework/9780123756794/ encyclopedia-of-health-economics\#book-description, https://www.azonano. com/suppliers.aspx?SupplierlD=1488.

7. Chandna SM, Da Silva-Gane M, Marshall C, Warwicker P, Greenwood RN, Farrington K. Survival of elderly patients with stage 5 CKD: comparison of conservative management and renal replacement therapy. Nephrol Dial Transplant. 2010;26(5):1608-14.

8. Hussain JA, Mooney A, Russon L. Comparison of survival analysis and palliative care involvement in patients aged over 70 years choosing conservative management or renal replacement therapy in advanced chronic kidney disease. Palliat Med. 2013;27(9):829-39.

9. Verberne WR, Geers AT, Jellema WT, Vincent HH, van Delden JJ, Bos WJW. Comparative survival among older adults with advanced kidney disease managed conservatively versus with dialysis. Clin J Am Soc Nephrol. 2016; 11(4):633-40.

10. Okamoto I, Tonkin-Crine S, Rayner H, Murtagh FE, Farrington K, Caskey F, et al. Conservative care for ESRD in the United Kingdom: a national survey. Clin J Am Soc Nephrol. 2015:10(1):120-6.

11. Morton RL, Webster AC, McGeechan K, Howard K, Murtagh FE, Gray NA, et al. Conservative management and end-of-life care in an Australian cohort with ESRD. Clin J Am Soc Nephrol. 2016;11(12):2195-203.

12. Belasco AG, Sesso R. Burden and quality of life of caregivers for hemodialysis patients. Am J Kidney Dis. 2002;39(4):805-12.

13. Tong A, Sainsbury P, Craig JC. Support interventions for caregivers of people with chronic kidney disease: a systematic review. Nephrol Dial Transplant. 2008:23(12):3960-5.

14. Campbell AR. Family caregivers: caring for aging end-stage renal disease partners. Adv Ren Replace Ther. 1998;5(2):98-108.

15. Asti T, Kara M, Ipek G, Erci B. The experiences of loneliness, depression, and social support of Turkish patients with continuous ambulatory peritoneal dialysis and their caregivers. J Clin Nurs. 2006;15(4):490-7.

16. Tong A, Lowe A, Sainsbury P, Craig JC. Experiences of parents who have children with chronic kidney disease: a systematic review of qualitative studies. Pediatrics. 2008;121(2):349-60.

17. White $Y$, Grenyer BF. The biopsychosocial impact of end-stage renal disease: the experience of dialysis patients and their partners. J Adv Nurs. 1999;30(6): 1312-20.

18. Tsai T-C, Liu S-I, Tsai J-D, Chou L-H. Psychosocial effects on caregivers for children on chronic peritoneal dialysis. Kidney Int. 2006;70(11):1983-7.

19. Shimoyama S, Hirakawa O, Yahiro K, Mizumachi T, Schreiner A, Kakuma T. Health-related quality of life and caregiver burden among peritoneal dialysis patients and their family caregivers in Japan. Perit Dial Int. 2003; 23(Supplement 2):S200-S5. 
20. Schneider RA. Fatigue among caregivers of chronic renal failure patients: a principal components analysis. Nephrol Nurs J. 2003;30(6):629-35.

21. Cukor D, Cohen SD, Peterson RA, Kimmel PL. Psychosocial aspects of chronic disease: ESRD as a paradigmatic illness. J Am Soc Nephrol. 2007; 18(12):3042-55.

22. Walker RC, Hanson CS, Palmer SC, Howard K, Morton RL, Marshall MR, et al. Patient and caregiver perspectives on home hemodialysis: a systematic review. Am J Kidney Dis. 2015;65(3):451-63.

23. Morton RL, Tong A, Howard K, Snelling P, Webster AC. The views of patients and carers in treatment decision making for chronic kidney disease: systematic review and thematic synthesis of qualitative studies. BMJ. 2010;340:c112-c.

24. Charlesworth G, Shepstone L, Wilson E, Thalanany M, Mugford M, Poland F. Does befriending by trained lay workers improve psychological well-being and quality of life for carers of people with dementia, and at what cost? A randomised controlled trial. Health Technol Assess. 2008;12(4):1-78.

25. Jansen AP, van Hout HP, van Marwijk HW, Nijpels G, de Bruijne MC, Bosmans $J$ E, et al. (Cost)-effectiveness of case-management by district nurses among primary informal caregivers of older adults with dementia symptoms and the older adults who receive informal care: design of a randomized controlled tria [ISCRTN83135728]. BMC Public Health. 2005;5(1):133.

26. Patel A, Knapp M, Evans A, Perez I, Kalra L. Training care givers of stroke patients: economic evaluation. BMJ. 2004;328(7448):1102.

27. Bilcke J, Van Damme P, Beutels P. Cost-effectiveness of rotavirus vaccination: exploring caregiver ( $\mathrm{s}$ ) and "no medical care"disease impact in Belgium. Med Decis Mak. 2009;29(1):33-50.

28. Gage H, Kaye J, Owen C, Trend P, Wade D. Evaluating rehabilitation using cost-consequences analysis: an example in Parkinson's disease. Clin Rehabil. 2006;20(3):232-8

29. Al-Janabi H, Flynn TN, Coast J. QALYs and Carers. PharmacoEconomics. 2011;29(12):1015-23

30. Williams A. Economics of coronary artery bypass grafting. Br Med J (Clin Res Ed). 1985;291(6491):326-9.

31. McDaid D. Estimating the costs of informal care for people with Alzheimer's disease: methodological and practical challenges. Int J Geriatr Psychiatry. 2001;16(4):400-5

32. Scholte W, Haan RD, Pijnenborg J, Limburg M, Gvd B. Assessment of burden in partners of stroke patients with the sense of competence questionnaire. Stroke. 1998:29(2):373-9.

33. Jansen AP, van Hout HP, van Marwijk HW, Nijpels G, Gundy C, VernooijDassen MJ, et al. Sense of competence questionnaire among informal caregivers of older adults with dementia symptoms: a psychometric evaluation. Clin Pract Epidemiol Ment Health. 2007;3(1):11.

34. Al-Janabi H, Coast J, Flynn TN. What do people value when they provide unpaid care for an older person? A meta-ethnography with interview follow-up. Soc Sci Med. 2008;67(1):111-21.

35. Vandenbroucke JP, von Elm E, Altman DG, Gøtzsche PC, Mulrow CD, Pocock SJ, et al. Strengthening the reporting of observational studies in epidemiology (STROBE): explanation and elaboration. PLoS Med. 2007;4(10):e297.

36. Shah KK, Murtagh FEM, McGeechan K, Crail S, Burns A, Tran AD, et al. Health-related quality of life and well-being in people over 75 years of age with end-stage kidney disease managed with dialysis or comprehensive conservative care: a cross-sectional study in the UK and Australia. BMJ Open. 2019:9(5):e027776.

37. Brazier JE, Roberts J. The estimation of a preference-based measure of health from the SF-12. Med Care. 2004:42(9):851-9.

38. Brazier J, Roberts J, Deverill M. The estimation of a preference-based measure of health from the SF-36. J Health Econ. 2002;21(2):271-92.

39. Kharroubi SA, Brazier JE, Roberts J, O'Hagan A. Modelling SF-6D health state preference data using a nonparametric Bayesian method. J Health Econ. 2007;26(3):597-612.

40. Hoefman R, Al-Janabi H, McCaffrey N, Currow D, Ratcliffe J. Measuring caregiver outcomes in palliative care: a construct validation study of two instruments for use in economic evaluations. Qual Life Res. 2015;24(5):1255-73.

41. Nolan M, Grant G, Keady J. Understanding family care: a multidimensional model of caring and coping: Open University; 1996.

42. Goranitis I, Coast J, Al-Janabi H. An investigation into the construct validity of the Carer experience scale (CES). Qual Life Res. 2014;23(6):1743-52.

43. Walters SJ, Brazier JE. Comparison of the minimally important difference for two health state utility measures: EQ-5D and SF-6D. Qual Life Res. 2005; 14(6):1523-32
44. Belasco A, Barbosa D, Bettencourt AR, Diccini S, Sesso R. Quality of life of family caregivers of elderly patients on hemodialysis and peritoneal dialysis. Am J Kidney Dis. 2006;48(6):955-63.

45. Gray NA, Zuo L, Hong D, Smyth B, Jun M, De Zoysa J, et al. Quality of life in caregivers compared with dialysis recipients: the co-ACTIVE sub-study of the ACTIVE dialysis trial. Nephrology. 2019;24(10):1056-63.

46. Knowles S, Combs R, Kirk S, Griffiths M, Patel N, Sanders C. Hidden caring, hidden carers? Exploring the experience of carers for people with long-term conditions. Health Soc Care Commun. 2016;24(2):203-13.

47. Koopmanschap MA, van Exel NJA, van den Berg B, Brouwer WB. An overview of methods and applications to value informal care in economic evaluations of healthcare. Pharmacoeconomics. 2008;26(4):269-80.

48. Hanratty B, Lowson E, Holmes L, Addington-Hall J, Arthur A, Grande G, et al. A comparison of strategies to recruit older patients and carers to end-of-life research in primary care. BMC Health Serv Res. 2012;12:342.

49. Hazell CM, Jones CJ, Pandey A, Smith HE. Barriers to recruiting and retaining psychosis carers: a case study on the lessons learned from the Caring for Caregivers (C4C) trial. BMC Res Notes. 2019;12(1):810.

\section{Publisher's Note}

Springer Nature remains neutral with regard to jurisdictional claims in published maps and institutional affiliations.
Ready to submit your research? Choose BMC and benefit from:

- fast, convenient online submission

- thorough peer review by experienced researchers in your field

- rapid publication on acceptance

- support for research data, including large and complex data types

- gold Open Access which fosters wider collaboration and increased citations

- maximum visibility for your research: over $100 \mathrm{M}$ website views per year

At $\mathrm{BMC}$, research is always in progress.

Learn more biomedcentral.com/submissions 